\title{
SALIVARY NEUTROPHILS LEVEL AS AN INDICATOR OF BONE MARROW ENGRAFTMENT
}

\author{
Richard Pink $k^{\mathrm{a}}$, Jana Vondrakova ${ }^{\mathrm{b}}$, Peter Tvrdy ${ }^{\mathrm{a}}$, Petr Michla ${ }^{\mathrm{a}}$, Jindrich Pazdera ${ }^{\mathrm{a}}$, Edgar Faber ${ }^{\mathrm{b}}$, \\ Ivana Skoumalova ${ }^{\mathrm{b}}$, Karel Indrak ${ }^{\mathrm{b}}$
}

\author{
a Department of Oral and Maxillofacial Surgery, University Hospital, Olomouc, 775 20, Czech Republic, \\ b Department of Hemato-Oncology, University Hospital, Olomouc \\ e-mail: richard.pink@seznam.cz
}

Received: February 20, 2009; Accepted: October 13, 2009

Key words: Oral cavity rinsing/Neutrophils/Autologous peripheral stem cell transplantation

Aim: The aim of this study was to investigate the neutrophils level in saliva as an adequate alternative to other methods for evaluating the neutrophil engraftment after autologous stem cell transplantation (ASCT) in hemato-oncology.

Method: A total of 35 patients treated for non-Hodgkin's lymphoma or multiple myeloma were stomatologically examined before planned high-dose chemotherapy with ASCT. After removal of potential foci of odontogenic infection all the patients underwent transplantation and during the treatment they were monitored for the level of neutrophils in saliva as a possible early indicator of the neutrophil engraftment. Neutrophil levels in saliva were compared to the neutrophil level in blood and to the degree of oral mucositis (the nurses study).

Results: An increase of salivary neutrophils in the mouth rinse of $>25 \times 10^{\wedge} 6 / 1$ was identified as an early sign of successful neutrophil engraftment that occurred 1 to 2 days before the rise of neutrophils in peripheral blood ( $>0.5$ x 10^9/1).

Conclusions: Follow-up of neutrophil levels in saliva might be an adequate alternative to other methods for evaluating the neutrophil engraftment after ASCT in hemato-oncology.

\section{INTRODUCTION}

High dose chemotherapy with the support of autologous peripheral stem cell grafts (ASCT) has been considered now as standard treatment for a number of hematological malignancies. However, aggressive chemotherapy, apart from having systemic side effects, is also followed by severe oral mucositis with significant impact on the psychological well-being of the patient. To avoid this development, preventive dental intervention is necessary and this should take place prior to the start of the oncological treatment: all potential infectious foci must be healed, devitalized teeth have to be removed and patients must be instructed in the principles of oral hygiene. Developing a state of oral health and following-up levels of granulocytes in saliva after ASCT might be significant indicators of neutrophil engraftment.

\section{MATERIAL AND METHODOLOGY}

The sample included a total of 35 patients treated at the Department of Hemato-Oncology of the University Hospital, Olomouc in 2006-2008. All the patients were treated on the basis of established treatment protocols for non-Hodgkin's lymphomas and multiple myeloma. Before inclusion in the study, they signed a written informed consent to the treatment protocol approved earlier by the local institutional Ethical Committee.

At least 3 weeks before myeloablative chemotherapy was started, standard stomatological examination was carried out. This included OPG (Orthopantomogram) X-ray, as well as parodontological examination and removal of potential sources of mucous membrane mechanical irritation such as grinding of sharp edges of teeth, dental fillings and dentures. Patients preparation before the transplantation included also practice in the Stillman method of brushing teeth and instruction on the harmful effects of smoking, alcohol and consumption of irritating food during treatment. To remove potential foci of odontogenic infection, we extracted gangrenous teeth, teeth with $\mathrm{X}$ ray confirmed periostitis, partially erupted third molars with clinical symptoms of pericoronitis and teeth mobility of the $2^{\text {nd }}, 3^{\text {rd }}$ degrees with active periodontal pockets. We did not extract teeth imperfectly endodontically healed, which did not clinically respond to percussion and vitality tests and showed negative $\mathrm{X}$ ray findings. The start of the stomatological examination also included determination of PBI (Papilla Bleeding Index), CPITN (The Community Periodontal Index of Treatment Needs) and supragingival scaling. Before starting the chemotherapy, the patients included in the study went through one week treatment of a twice daily rinse with the oral antiseptic Listerine (Pfizer).

Patients with severe parodontitis who refused extraction and patients with poor oral hygiene who declined cooperation were excluded from the study.

From the hemato-oncological point of view all our patients were treated for non-Hodgkin's lymphomas and multiple myeloma according to established treat- 
ment protocols. (Table 1). In the case of non-Hodgkin's lymphoma, high-dose chemotherapy BEAM was used for the conditioning (BCNU, cytarabine, etoposide, and melphalan). In the case of multiple myeloma the treatment was monotherapy with high-dose (HD) melphalan in one dose of $200 \mathrm{mg} / \mathrm{m}^{2}$ infused over one hour. ASCT was performed in all patients with special isolation ${ }^{11}$ and using selective decontamination of GIT (gastro-intestinal tract) 24 hours after the performed myeloablative chemotherapy. Other prophylactic measures included application of fluconazole $200 \mathrm{mg}$ daily, co-trimoxazole $480 \mathrm{mg}$ twice a day and acyclovir $400 \mathrm{mg}$ three times a day. In patients unable of oral food intake the same antibiotics were given parenterally. In case of febrile neutropenia empiric broad spectrum antibiotics were applied according to the Institutional protocol. To accelerate the neutrophil engraftment, all patients with multiple myeloma received G-CSF (Granulocyte Colony Stimulating Factor) at a dose of $5 \mathrm{ug} / \mathrm{kg}$ starting on the day +7 after graft reinfusion until full neutrophil recovery. In patients with malignant lymphomas single dose of G-CSF was applied according to the protocol described earlier ${ }^{1}$.

Along with the examination of blood neutrophil levels, we quantitated the neutrophils present in saliva. Salivary sampling was started on day 0 the day of graft transfer. The patients rinsed their oral cavities with $10 \mathrm{ml}$ saline solution for a period of $30 \mathrm{sec}$ each morning before breakfast and before oral cavity hygiene. The sample was then centrifuged for at $200 \mathrm{~g}$ for $10 \mathrm{~min}$ and the supernatant fluid was carefully sucked away to leave $1 \mathrm{ml}$ sediment. The sediment was stained with methylviolet, showing neutrophils with a characteristic multi-lobulated shape and typical kernel nuclei that could be easily distinguished from the other cells and epithelial cells. The samples were observed on a light microscope and neutrophils were counted in 16 large squares of a Fuchs-Rosenthal chamber at a magnification of 50x. Over weekends and bank holidays the material was preserved in $2 \mathrm{ml} 39 \%$ formaldehyde, stored at $4^{\circ} \mathrm{C}$ and processed the first day following the weekend or bank holidays to ensure the continuity of evaluation ${ }^{2}$. Salivary samples were examined every day until successful neutrophil engraftment was confirmed.

\section{RESULTS}

A generally accepted indicator of successful engraftment is the achievement of the $0.5 \times 10^{\wedge} 9 / 1$ level of granulocytes in blood on 3 successive days. Determination of the granulocyte level in saliva is an alternative indicator. The granulocyte level marking a successful engraftment is $25 \times 10^{\wedge} 6 / 1$ on 2 successive days, counted in 16 fields of Fuchs-Rosenthal chamber ${ }^{3}$. Typical was a somewhat variable curve of neutrophil levels in saliva after autologous transplantation with a rapid decrease in neutrophils towards zero values, followed by a subsequent rapid rise as demonstrated in Graph 1.

In fourteen patients (patient 1, 3, 7, 14, 16, 17, 18, $22,25,28,29,31,32$ and 33) registered in our study the level of neutrophils in saliva indicating successful engraftment was achieved approximately 1-2 days sooner than in peripheral blood (Graph 2), (Table 3). In seven patients (patient 2, 8, 9, 13, 27, 34 and 35) the required increase was noticed both in saliva and peripheral blood on the same day (Graph 2, Table 3). Seven patients (patient 4, $12,19,21,23,24$ and 30) engrafted the bone marrow in peripheral blood sooner than in saliva (Graph 2, Table 3).

According to median leucocyte levels (WBC > $\left.0.5 \times 10^{\wedge} 9 / 1\right)$ all patients engrafted on day $12(9-18)$, patients with myeloma on day $12(10-13)$, patients with lymphoma on day 11 (9-18). In saliva according to the level of neutrophils $\left(>25 \times 10^{\wedge} 6 / 1\right)$ all patients engrafted on day 11 (9-17), patients with myeloma on day 11 (914), patients with lymphoma on day 11 (9-17), (Table 2).

In six cases (patient 5,10,11,15,20 and 26) we did not assess neutrophil levels in saliva, since the required values of $25 \times 10^{\wedge} 6 / 1$ (patient 10,11 and 26) were not achieved or to the contrary, because the persisting neutrophil levels (patient 5,15 and 20) had not reached zero or close to zero levels (Graph 2). We noticed that the required level of neutrophils in saliva had not been achieved mostly in patients without teeth, where the primary entering level of neutrophils is lower compared to patients with teeth. In one case (patient 6) neutrophil levels indicating successful engraftment of the bone marrow had not been achieved in saliva and blood (Graph 2).

Table 1. An examined collection of patients.

\begin{tabular}{|l|c|c|c|c|l|}
\hline Diagnosis & $\begin{array}{c}\text { Number } \\
\text { of patients }\end{array}$ & Women & Men & $\begin{array}{c}\text { Average age } \\
\text { (years) }\end{array}$ & $\begin{array}{l}\text { Chemotherapy } \\
\text { regimen }\end{array}$ \\
\hline $\begin{array}{l}\text { Non-Hodgkin's } \\
\text { lymphoma }\end{array}$ & 20 & 9 & 11 & 50 & BEAM \\
\hline Multiple Myeloma & 11 & 5 & 6 & 57 & HD melphalan \\
\hline Hodgkin lymphoma & 4 & 3 & 1 & 36 & BEAM \\
\hline Total & $\mathbf{3 5}$ & $\mathbf{1 7}$ & $\mathbf{1 8}$ & $\mathbf{5 0}$ & \\
\hline
\end{tabular}




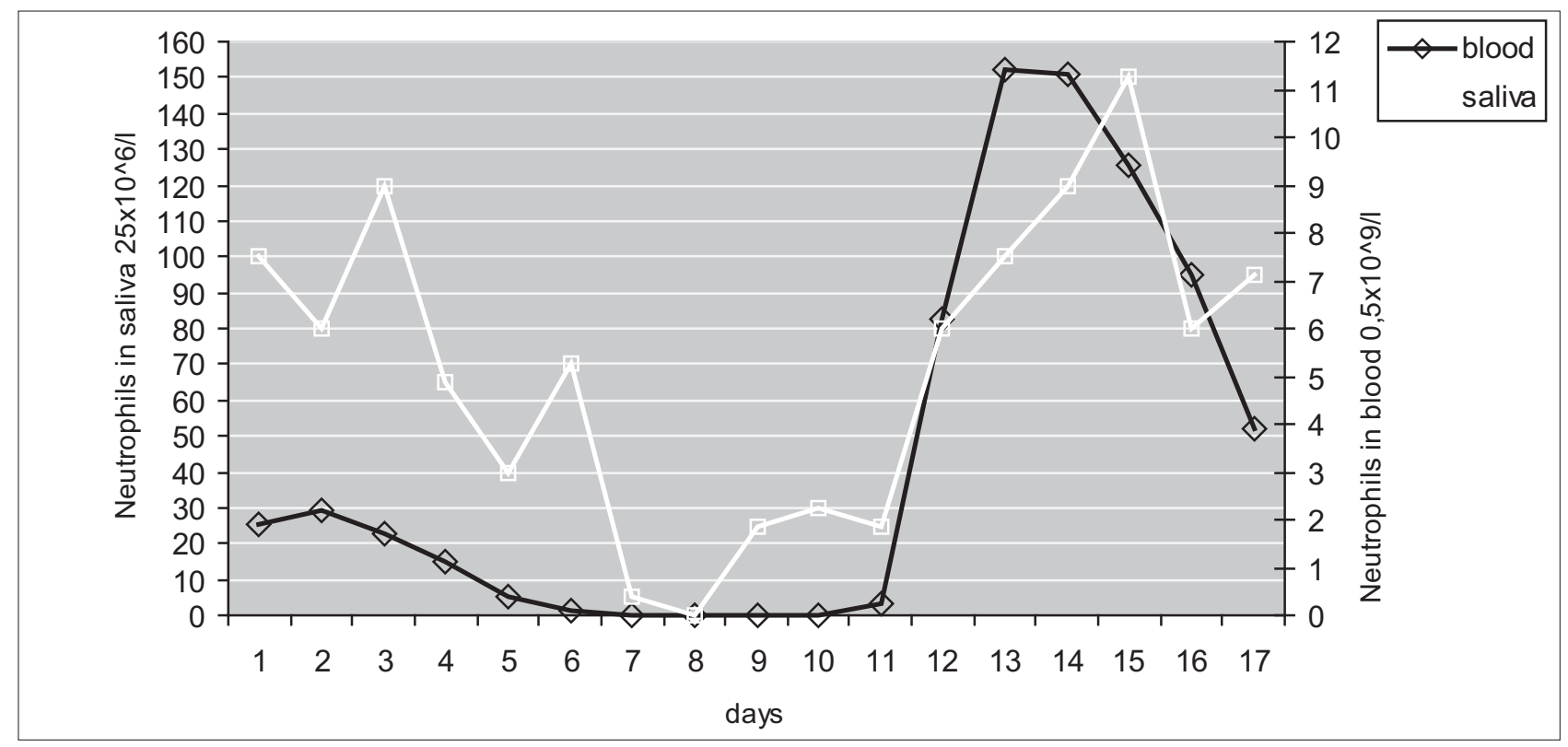

Graph 1. Variability in neutrophil levels in saliva and blood in a group of hemato-oncological patients after autological bone marrow transplantation and immunosuppressive treatment.

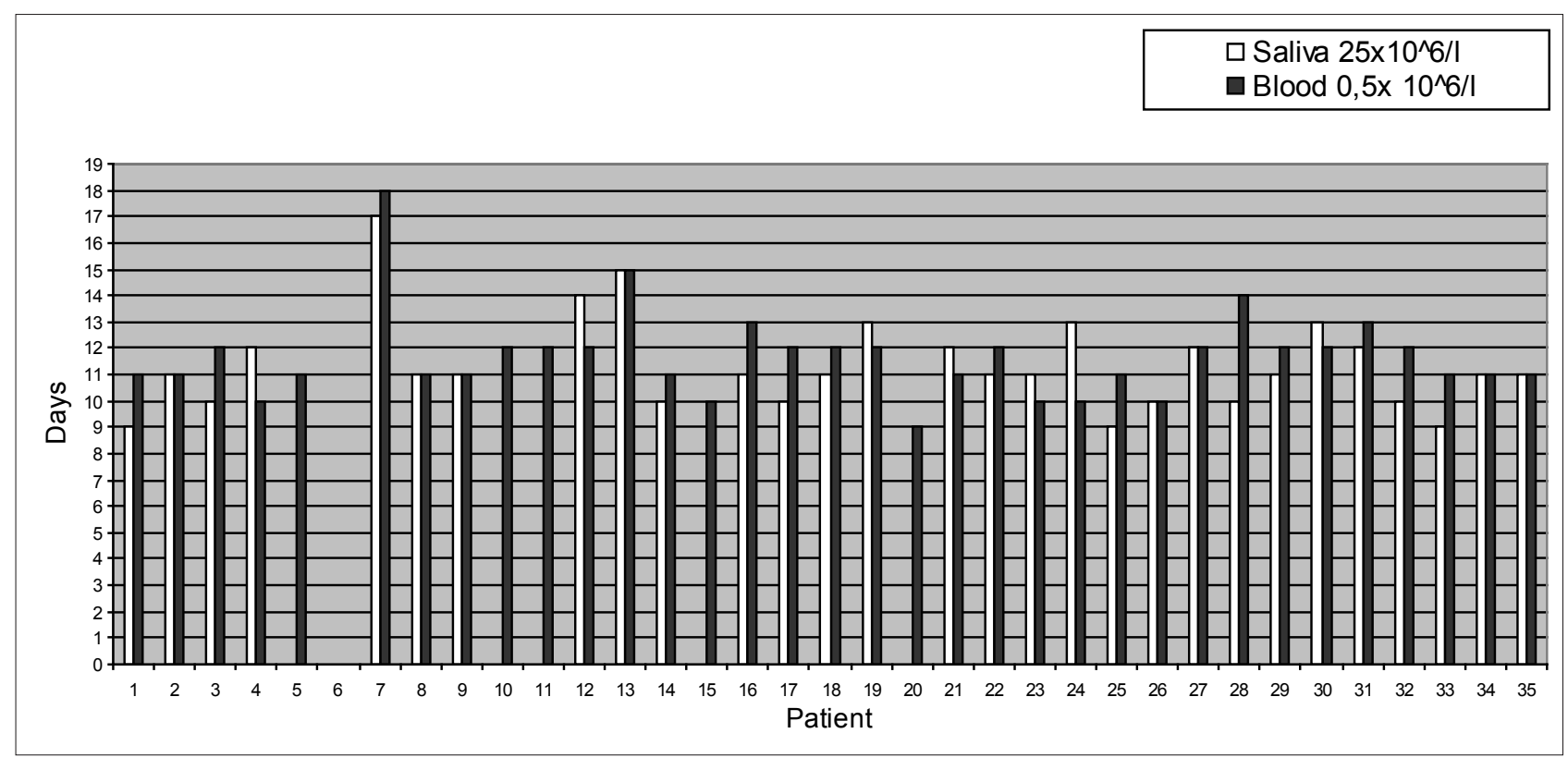

Graph 2. Time difference between reaching the required levels of neutrophils in saliva and blood.

To assess the success of the hemato-oncologic treatment it was very important to determine the entering neutrophil level in saliva before starting chemotherapy. The group of patients with teeth showed higher entering neutrophil levels in saliva compared to patients without teeth. (Graph 3 and 4$)^{4}$. The average neutrophil level in patients with teeth was $171 \times 10^{\wedge} 6 / 1$, while in those without teeth it was $24 \times 10^{\wedge} 6 / 1$.

In 9 patients the neutrophil levels did not decrease to zero or even close to zero (zero level represented the lowest achieved level). Of these, 3 patients treated for myeloma (patients 6,7,8) and 6 patients treated for NHL (patients 10, 14, 15, 16, 17 and 18) - (Graph 5 and 6)
To determine the physiological neutrophil level in saliva, saliva samples were obtained from 22 healthy volunteers by rinsing the oral cavity by the method mentioned above. The average neutrophil level in saliva was $174 \mathrm{x}$ $10^{\wedge} 6 / 1$, Graph 5 .

\section{DISCUSSION}

Preventive dental intervention is necessary and this should take place prior to the start of the oncological treatment. A standard part of preparing for ASCT is also using oral antiseptics. A number of publications focused 
Table 2. Median values of engraftment according tolevels of neutrophils in saliva and blood.

\begin{tabular}{|l|c|c|}
\hline $\begin{array}{c}\text { Engraftment } \\
\text { (days) }\end{array}$ & $\begin{array}{c}\text { WBC }> \\
0.5 \times 10^{\wedge} 9 / 1\end{array}$ & $\begin{array}{c}\text { Saliva }> \\
25 \times 10^{\wedge} 6 / 1\end{array}$ \\
\hline all & $12(9-18)$ & $11(9-17)$ \\
\hline myeloma & $12(10-13)$ & $11(9-14)$ \\
\hline lymphoma & $11(9-18)$ & $11(9-17)$ \\
\hline
\end{tabular}

Note:

All patients: 3 patients (No. 5, 15, 20) without decrease in saliva, 3 patients (No. 10, 11, 26) without engraftment in saliva, 1 patient (No. 6) engraftment neither in saliva nor in blood

MM: 2 patients (No. 5, 15) without decrease in saliva, 2 patients (No. 10, 11) without engraftment in saliva

NHL+MH: 1 patient (No. 26) without engraftment in saliva, 1 patient (No. 6) engraftment neither in saliva nor in blood, 1 patient (No. 20) without decrease in saliva

Table 3. Engraftment in time difference according to neutrophil level in saliva and blood.

\begin{tabular}{|c|c|c|c|}
\hline & Total & MM & $\mathrm{NHL}+\mathrm{MH}$ \\
\hline No difference in engraftment & 7 patients & 2 patients & 5 patients \\
\hline Neutrophils sooner in saliva & 14 patients & 3 patients & 11 patients \\
\hline Neutrophils sooner in blood & 7 patients & 2 patients & 5 patients \\
\hline
\end{tabular}

\section{Entering neutrophil levels in saliva by patients without teeth}
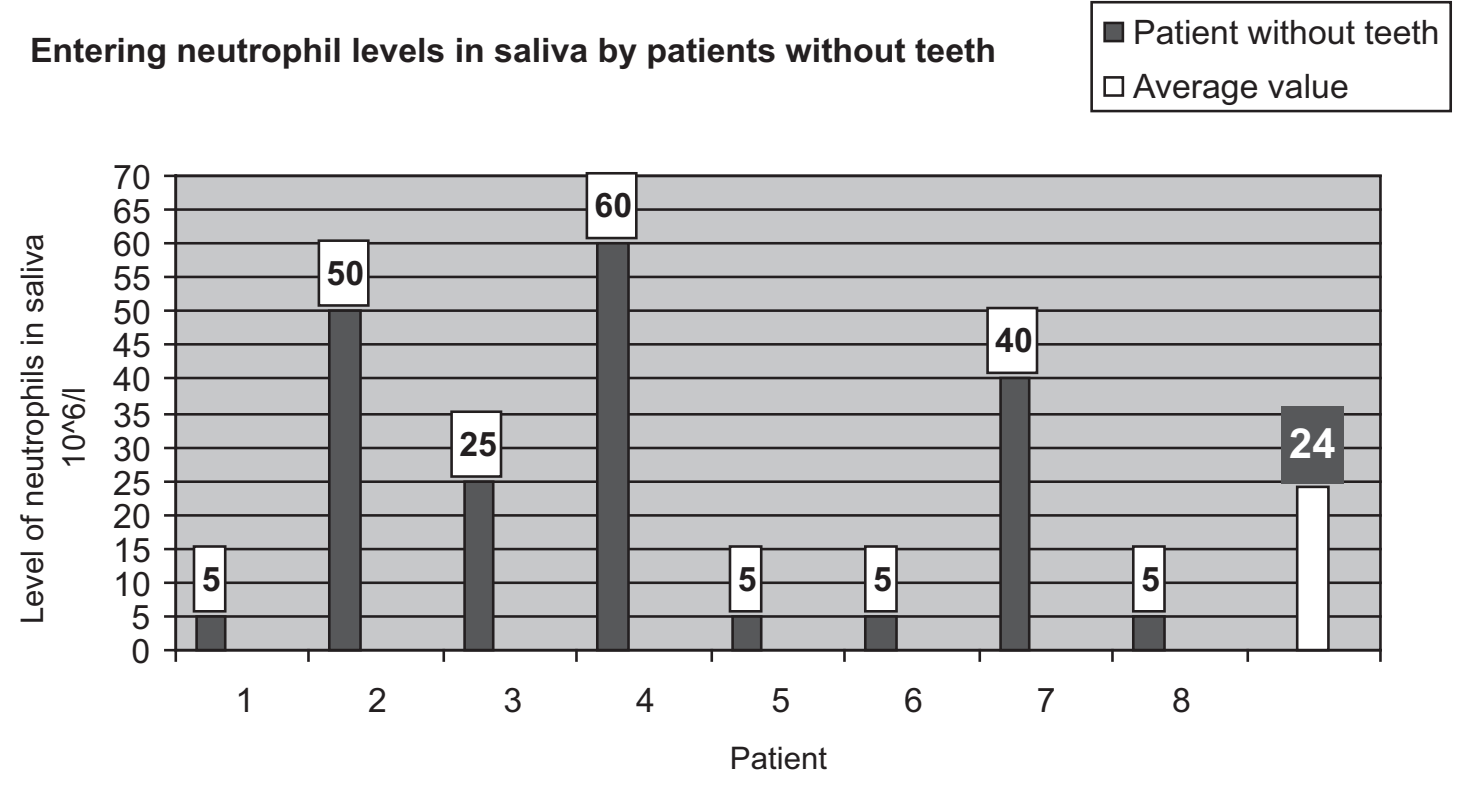

Graph 3. Entering neutrophil levels in saliva from patients without teeth.

on oral antiseptics but their conclusions are equivocal. For example Vokurka et al..$^{5}$ found no difference between the use of iodide preparations as oral antiseptics and saline. The product, Listerine (Pfizer) we used is an antiseptic agent containing essential oils (thymol, eucalyptol, menthol, methyl salicylate) and alcohol. Its antibacterial effect is based on blockade of cellular metabolism ${ }^{6}$. In addition it has an anti-mycotic and anti-viral effect (Miller et al $)^{7}$. Listerine is very good at preventing plaque and removing existing plaque as well. Moreover it does not disturb the balance of bacterial flora in the oral cavity and does not stain dental enamel even after long-term use ${ }^{8,9}$. Its therapeutic effect on inflammatory parodontal disease is also noteworthy (Graph 8).

A saliva neutrophil level is nowadays already frequent used method to determine severity of periodontal diseas- 


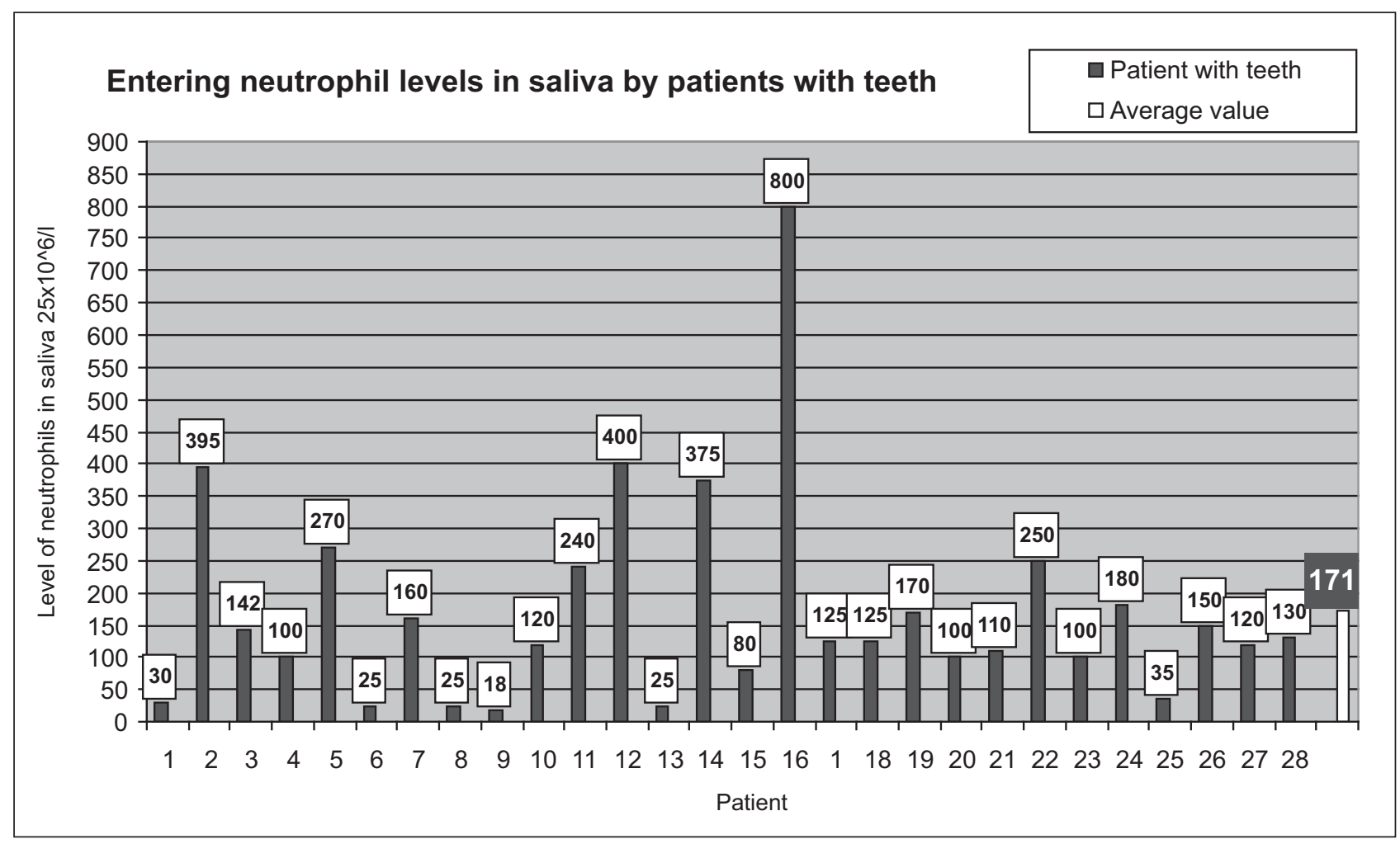

Graph 4. Entering neutrophil levels in saliva from patients with teeth.

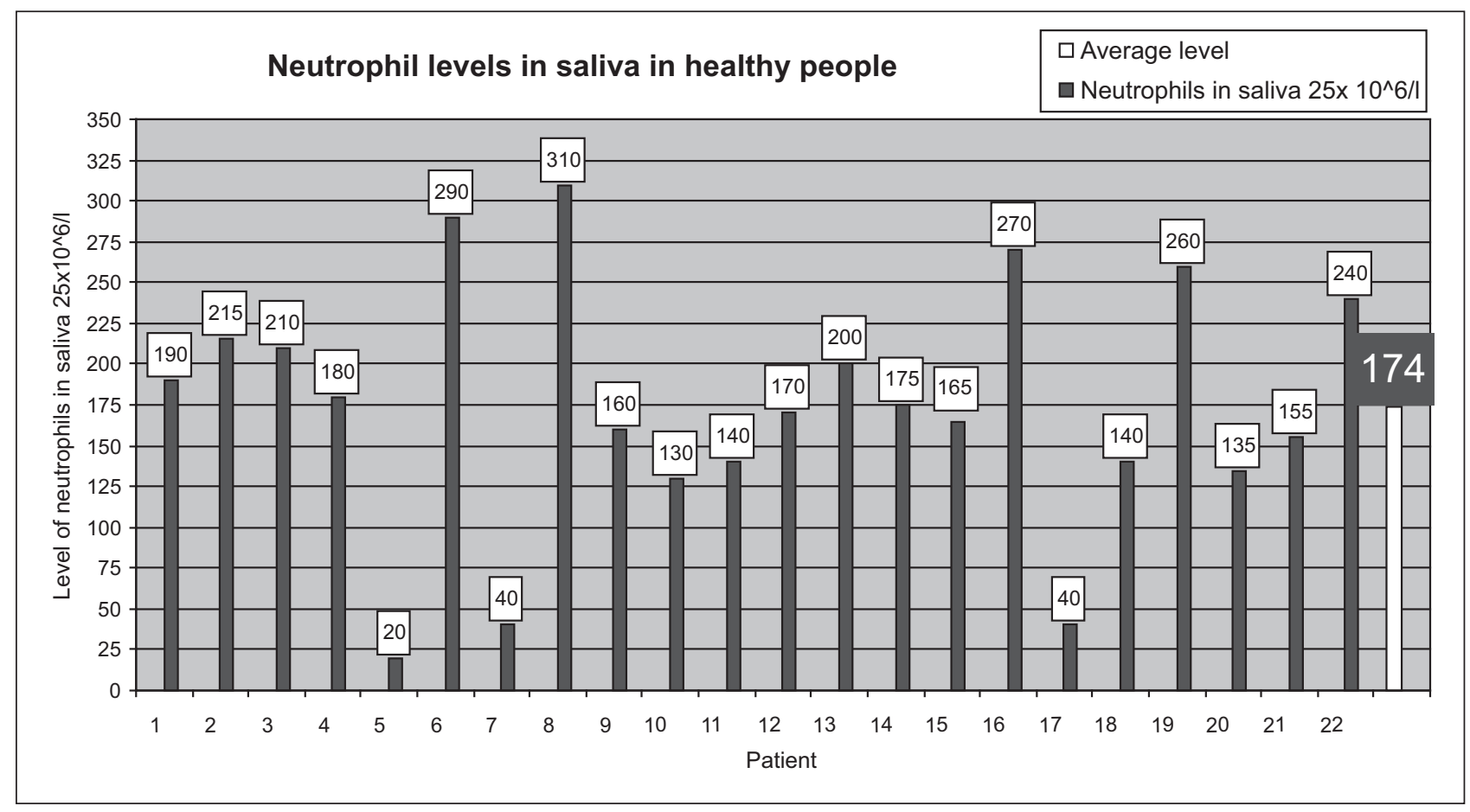

Graph 5. Check group: Neutrophil level in saliva from healthy people.

es. Recently, some studies, focused on detection saliva neutrophils count as a grade of severity of periodontal disease and treatment response were published ${ }^{2,10-12}$.

To avoid misinterpretation of some results, the responsible treatment of periodontal diseases must precede ASCT.
This was the reason why patients suffering from severe grade of periodontal disease (see Graph No.6) were excluded of our study.

In our sample of 35 patients treated for non-Hodgkin's lymphomas and multiple myeloma by high-dose chemotherapy with ASCT, successful engraftment was marked 
by an increase in salivary neutrophil levels an average of 1-2 days earlier than in peripheral blood ${ }^{13}$.

Nowadays there are no studies, explaining earlier neutrophil penetration to the oral cavity in comparison to their manifestation in peripheral blood. Within the context of this should be refered the diversity of saliva and oral fluid which contains the saliva by itself, gingival cervical fluid, sloughed oral epithelial cells, food debris, and bacteria and their product ${ }^{14-18}$.

In our study we found a higher level of salivary neutrophils in patients with teeth then in edentulous. We support the conclusions of Wright et al. ${ }^{4}$ who found very low salivary neutrophil level in four edentulous patients. Just the presence of dental plaque and oral bacteria (over 500 bacterial species are present in the mouth) could explain the chemotaxis of the neutrophils into the oral cavity.

The time interval of successful engraftment was considerably influenced by the myeloablative chemotherapy of non-Hodgkin's lymphomas ${ }^{3}$. A time difference between reaching favourable levels of neutrophils in saliva and in blood might correspond to the risks of infection and septic conditions occurring after graft reinfusion ${ }^{3}$. The longer this time interval is, the smaller the risk of infectious complications. This view is based on an assumption of gradual "preferential" feeding of tissues with neutrophils. The higher the neutrophil level in a tissue, the greater the self-defensive ability of the organism. This theory, however, would rather support reaching of neutrophils into the oral cavity through tissue penetration.

There are still doubts over the methodology of determining the physiological level of neutrophils in saliva. Wright et al. ${ }^{4}$ did rinses of the oral cavity in the forementioned manner using a number of volunteers with good oral health. The neutrophil level in saliva oscillated between $1,3 \times 10^{\wedge} 5 / 1$ and $10,8 \times 10^{\wedge} 5 / 1$. Although we did not evaluate this parameter in our small sample of patients, we have never observed such wide variation in neutrophils levels. To get comparable results it is necessary to maintain a time schedule for saliva sampling since the level of salivary neutrophils during the day tends to fluctuate as a result of the consumption of liquids and food. The connection between the level of neutrophils in saliva and blood is also confirmed by increasing levels of neutrophils after administration of growth factors. Lieschke et al. ${ }^{19}$ found a several times greater increase in levels of neutrophils in saliva as well as in blood in G-CSF treated patients where levels of neutrophils in saliva increased a few days earlier than in peripheral blood, compared to untreated patients.

Croatian authors advert to different phagocytic function of salivary neutrophils in comparison to neutrophils in peripheral blood ${ }^{20}$. They compare phagocytic function of salivary neutrophils of healthy volunteers with their activity in patients suffered from oral lichen planus and acute recurrent aphtous ulceration. Our experience is similar (the nurses study): oral mucositis turned to better just after appearance of neurtophils in oral fluid ${ }^{21}$.

The radicality of the stomatological preparation of the

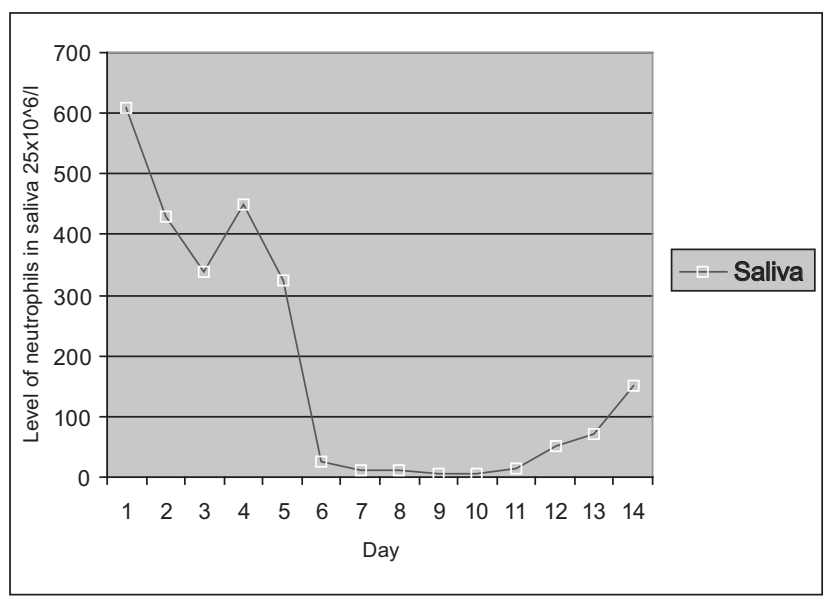

Graph 6. Neutrophil levels in saliva from patient with parodontitis. High entering neutrophil levels in saliva and resulting steep decrease as a proof of good response to Listerine treatment.

patients before stem cell transplantation and before surgery must be also carefully considered. It seems that while this preparation is being planned, the type of transplantation and the aggressiveness of the chemotherapy should be taken into account. Strictly radical methods are recommended in patients before allogenic transplantation. Our experience confirms Starosta's and Faber's view ${ }^{22,23}$ that before ASCT less radical preparation is necessary - it is unnecessary to extract teeth, even if they are not quite perfectly endodontically treated unless they display X ray confirmed peri-apical finding. In any event, it is important to eliminate the risks of mechanical irritation of soft tissues through sharp tooth edges, dental fillings, dentures or plaque to obviate mucosal lesions.

Our results confirmed that parodontal diseases can influence the salivary neutrophil level.

\section{CONCLUSION}

In spite of a small group of analyzed patients we can conclude that monitoring the level of the neutrophils in saliva after ASCT appears to be practical and useful. A non-invasive easy sampling of biological material can be used for earlier signalling of successful engraftment.

Good cooperation between the stomatologist and the hemato-oncologist results in both the reduced frequency and gravity of oral mucositis as well as in eliminating the risks of potential odontogenic treatment complications. Oral health in this connection serves as an indicator of general health and signalizes a risk of complications after high-dose chemotherapy. The practical use of determining the level of neutrophils in saliva as an indicator of treatment success in hemato-oncology can also lead to modifications in the treatment protocol and to essential financial savings. To confirm these conclusions, a study of a larger set of patients will be necessary. 


\section{REFERENCES}

1. Faber E, Pytlík R, Slabý J, Zapletalová J, Kozák T, Raida L, Papajik $\mathrm{T}$, Žikešová $\mathrm{E}$, Marešová I, Hamouzová $\mathrm{M}$, Indrák $\mathrm{K}$, Trněný $\mathrm{M}$. Individually determined dosing of filgrastim after autologous peripheral stem cell transplantation in patients with malignant lymphoma - results of a prospective multicenter controlled trial Europ J of Haematol 2006; 77(6): 493-500.

2. Bender JS, Thang H, Glogauer M. Novel rinse assay for the quantification of oral neutrophils and the monitoring of chronic periodontal disease. J Periodontol, Res 2006; 41: 214-220.

3. Cheretakis C, Dror Y, Glogauer M. A noninvasive oral rinse assay to monitor engraftment, neutrophil tissue delivery and susceptibility to infection following HSCI in pediatric patients. Bone Marrow Transplant 2005; 36: 227-232.

4. Wright DG, Meierovics AI, Foxley JM. Assessing the delivery of neutrophils to tissues in neutropenia. Blood 1986; 67: 1023-1030.

5. Vokurka S, Bystřická E, Koza V, et al. The comparative effects of providone-iodine and normal saline mouthwashes on oral mucositis in patients after high-dose chemotherapy and APBSCT - results of a randomized multicentre study. Support Care Cancer 2002; 13: 554-558.

6. Fine DH. Mouthrinces as adjunct for plaque and gingivitis management. A status report for the Am J Dent 1988; 1: 259-263.

7. Miler TF, Silva A, Ferreira SM, Jabra-rizk MA, Kelley JI, Depaola LG. Efficacy of Listerine antiseptic in reducing viral contamination of saliva. J Clin Periodontol 2005; 32: 341-346.

8. Minah GE, Depaola LG, Overholser CD, Miller TF, Niehaus C, Lamm RA, Ross NM, Dills S.S. Effects of 6 months use of an antiseptic mouthrinse on supragingival dental plaque microflora. J Clin Periodontol 1989; 15: 347-352.

9. Walker C, Clark W, Tyler K, Ross N, Dill S. Evaluation of microbial shifts following long-term antiseptic mouthrinse use. J Periodontol 1997; 48: 646-649.

10. Klinkhamer JM. Quantitative evaluation of gingival and periodontial disease. The orogranulocyte migratory rate. J Periodontol 1968; 6: 207.

11. Ljungman P, Urbano-Ispizua A, Cavazzana-Calvo M, et al. Allogeneic and autologous transplantation for haematological diseases, solid tumours and immune disorders: definitions and current practice in Europe. Bone Marrow Transplant 2006; 37: 439-449.
12. Loe H. Silness Journal Periodontal disease in pregnancy. Prevalence and severity. Acta odent scan 1963; 25: 533.

13. Figueredo CM, Fischer RG, Gustafsson A. Aberrant neutrophil reactions in periodontis. J Periodontol 2005; 76: 951-955.

14. Gorgung A, Knight DR, Wright GD, Use of oral mucosal neutrophil counts to detect the onset and resolution of profound neutropenia following high-dose myelosuppressive chemotherapy. Am J Hematol 2003; 72: 13-19.

15. Burlage FR, Pijpe J, Coppes RP, et al. Variability of flow rate when collecting stimulated human parotid saliva. European Journal of Oral Sciences 2005; 113(5): 386-90.

16. Vissink A, Spijkervet FK, Van Nieuw, Amerongen A. Aging and saliva: a review of the literature. Special Care in Dentistry 1996; 16(3): 95-103

17. Wu AJ, Baum BJ, Ship JA. Extended stimulated parotid and submandibular secretion in healthy young and old population. Journals of Gerontology 1995; 50A(1): 45-8.

18. Schenkels LCPM, Veerman ECI, Nieuw Amerongen AV. Biochemical composition of human saliva in relation to other mucosal fluids. Crticial Reviews in Oral Biology \& Medicine 1995; 6: $161-75$.

19. Veerman ECI, Van Den Kejbus Pam, Nieuw Amerongen AV. Human glandular salivas: their separate collection and analysis. European Journal of Oral Sciences 1996; 104: 346-52.

20. Lieschke GJ, Ramenghi U, O'Connor MP, Sheridan W, Szer J, Morstyn G. Studies of oral neutrophils levels in patients receiving G-CSF after autologous marrow transplantation, British Journal of Haematology 1992; 82: 589-595.

21. Lukač J, Mravak - Stipetič et al. Phagocytic functions of salivary neutrophils in oral mucous membrane diseases. J Oral Pathol Med 2003; 32: 271-4.

22. Rubenstein E, Peterson D, Schubert M, et al. Clinical practice guidelines for prevention and treatment of cancer therapy - induced oral and gastrointestinal mucositis. Cancer 2004; 100: 2026-2046.

23. Starosta M, Faber E. Stomatitis u nemocných po autologní transplantaci hemopoetických kmenových buněk, Praktické zubní lékařství 2000; 5:131-136.

24. Bartáková V. Problémy stomatologického ošetřování u vybraných skupin rizikových pacientů, Česká Stomatologie 1986; 4: 255-260. 
